\title{
GIS-based Association Between PM10 and Allergic Diseases in Seoul: Implications for Health and Environmental Policy
}

\author{
SungChul Seo, ${ }_{1}^{1}$ Dohyeong Kim, ${ }_{1}^{2 *}$ Soojin Min, ${ }_{1}^{2}$ Christopher Paul, ${ }^{3}$ Young Yoo, ${ }^{1,4}$ Ji Tae Choung ${ }^{1,4}$ \\ 'The Environmental Health Center for Asthma, Korea University, Seoul, Korea \\ ${ }^{2}$ School of Economic, Political and Policy Sciences, the University of Texas at Dallas, Richardson, TX, United States \\ ${ }^{3}$ Duke Global Health Institute, Duke University, Durham, NC, United States \\ ${ }^{4}$ Department of Pediatrics, College of Medicine, Korea University, Seoul, Korea
}

This is an Open Access article distributed under the terms of the Creative Commons Attribution Non-Commercial License (http://creativecommons.org/licenses/by-nc/3.0/) which permits unrestricted non-commercial use, distribution, and reproduction in any medium, provided the original work is properly cited.

Purpose: The role of PM10 in the development of allergic diseases remains controversial among epidemiological studies, partly due to the inability to control for spatial variations in large-scale risk factors. This study aims to investigate spatial correspondence between the level of PM10 and allergic diseases at the sub-district level in Seoul, Korea, in order to evaluate whether the impact of PM10 is observable and spatially varies across the subdistricts. Methods: PM10 measurements at 25 monitoring stations in the city were interpolated to 424 sub-districts where annual inpatient and outpatient count data for 3 types of allergic diseases (atopic dermatitis, asthma, and allergic rhinitis) were collected. We estimated multiple ordinary least square regression models to examine the association of the PM10 level with each of the allergic diseases, controlling for various sub-district level covariates. Geographically weighted regression (GWR) models were conducted to evaluate how the impact of PM10 varies across the sub-districts. Results: PM10 was found to be a significant predictor of atopic dermatitis patient count $(P<0.01)$, with greater association when spatially interpolated at the sub-district level. No significant effect of PM10 was observed on allergic rhinitis and asthma when socioeconomic factors were controlled for. GWR models revealed spatial variation of PM10 effects on atopic dermatitis across the sub-districts in Seoul. The relationship of PM10 levels to atopic dermatitis patient counts is found to be significant only in the Gangbuk region $(P<0.01)$, along with other covariates including average land value, poverty rate, level of education and apartment rate $(P<0.01)$. Conclusions: Our findings imply that PM10 effects on allergic diseases might not be consistent throughout Seoul. GIS-based spatial modeling techniques could play a role in evaluating spatial variation of air pollution impacts on allergic diseases at the sub-district level, which could provide valuable guidelines for environmental and public health policymakers.

Key Words: Atopic dermatitis; asthma; allergic rhinitis; particulate matter; spatial analysis

\section{INTRODUCTION}

Allergic diseases, including atopic dermatitis, asthma, and allergic rhinitis, are prevalent in South Korea, affecting almost 9 million people of all ages, with total treatment expenses of approximately 600 million USD per year. ${ }^{1}$ These are multifactorial diseases caused by a variety of genetic and environmental factors. ${ }^{2}$ Multiple studies have investigated associations between allergic diseases, mainly asthma and atopic dermatitis, and various environmental and behavioral risk factors, such as mold exposure, indoor chlorinated swimming pools, indoor smoking, and frequency of indoor ventilation and cleaning. ${ }^{3-5}$ In particular, a rise in allergic disease in many countries has been attributed to increased exposure to air pollutants. ${ }^{6,7}$ Numerous studies around the world have demonstrated association between air pollutants such as $\mathrm{NO}_{2}, \mathrm{SO}_{2}$, and $\mathrm{O}_{3}$, as well as PM10, and the symptoms of allergic diseases. ${ }^{6,8-13}$

Among ambient air pollutants, PM10 has drawn attention for a potential association with several types of allergic diseases, such as asthma, atopic dermatitis, and allergic rhinitis. While the number of studies examining the association between outdoor air pollutants, including PM10, and atopic dermatitis is limited ${ }^{14}$ a clinical study found that exposure to PM10 was associated with atopic dermatitis. ${ }^{15}$ Regarding asthma and allergic rhinitis, epidemiological study results are mixed. PM10 is

Correspondence to: Dohyeong Kim, PhD, School of Economic, Political and Policy Sciences, The University of Texas at Dallas, 800 W Campbell Road, Richardson, TX 75080, United States.

Tel: +1-972-883-3512; Fax: +1-972-883-6297; E-mail: dohyeong.kim@utdallas.edu Received: February 3, 2015; Revised: May 4, 2015; Accepted: May 14, 2015

- There are no financial or other issues that might lead to conflict of interest. 
likely to contribute to exacerbating symptoms of asthma, ${ }^{16}$ but it is not clear whether PM10 increases the probability of inducing asthma. ${ }^{17}$ It is also reported that the effect of PM10 was inconsistent in a number of different regression analyses. ${ }^{18}$ As for allergic rhinitis, a number of studies indicated a positive relationship between the disease and exposure to PM10. ${ }^{13,19,20}$ Some studies, however, reported no significant association. ${ }^{21,22}$ The role of PM10 levels in the development of allergic diseases, particularly asthma and allergic rhinitis, is controversial.

While clinical studies have investigated the relationship between PM10 and allergic diseases based on the symptoms of selected study participants, ${ }^{15,19,22}$ epidemiological studies have examined this association employing observed data, such as patient records and survey data..$^{13,16,20,21,23}$ Patient records are typically aggregated at a certain regional level and routinely available. Studies looking at individual outcomes from clinical or epidemiological studies often face a sampling bias that does not accommodate spatial effects of pollutants. By incorporating large-scale spatial variations in the risk factors, the dynamics between the prevalence of allergic diseases and air pollutant levels, particularly PM10 in our case, would appear differently. From the perspective of public health policy, looking at largescale patterns is important as regional environmental factors could be related to disparities in health outcomes. ${ }^{24} \mathrm{~A}$ study in the Bronx, New York City investigated spatial correspondence between environmental risk factors and allergic diseases to identify spatially disproportionate environmental burdens associated with the diseases from a standpoint of environmental health justice. $^{25}$

Moreover, few studies have considered other covariates, including socioeconomic variables and meteorological data, in measuring a spatial association between ambient air pollutants and allergic diseases, ${ }^{26}$ although there are many confounding factors in determining the etiology of allergic diseases. ${ }^{27,28}$ The impacts of socioeconomic factors have not been sufficiently considered and the effects of air pollution on asthma symptoms vary depending on regional socioeconomic status. ${ }^{29}$ Socioeconomic factors are likely important in explaining differential outcomes in allergic diseases, ${ }^{30}$ and regional socioeconomic levels were associated with asthma-related hospital admissions affected by air pollution..$^{28,29}$

Thus, our study aims to examine spatial variability in how the level of PM10 is associated with the prevalence of 3 allergic diseases (atopic dermatitis, asthma, and allergic rhinitis) in Seoul, Korea by using inpatient and outpatient data aggregated at the sub-district level. Since there are only 25 monitoring stations measuring the level of PM10 on a daily basis in Seoul (1 per each of the 25 districts), our study employs a spatial interpolation technique to allow them to correspond with the disease prevalence data as calculated for the 424 sub-districts in the city. A series of multiple regression models are estimated to assess the impact of PM10 on the prevalence of each allergic dis- ease, with relevant socioeconomic and meteorological variables at the regional level controlled. Geographically weighted regression (GWR) models are also run to investigate regional variation in the findings. Our approach allows for the identification of more specific areas (i.e. sub-districts instead of districts) with the highest risks of allergic diseases, which is valuable for policy design and implementation.

\section{MATERIALS AND METHODS}

We conducted a cross-sectional study examining ecological association between PM10 and the prevalence of allergic diseases in the city of Seoul, South Korea. The numbers of patients per 10,000 inhabitants for asthma, atopic dermatitis, and allergic rhinitis in 424 sub-districts of Seoul in 2011 were calculated respectively, based on data collected by the National Health Insurance Corporation (NHIC) of South Korea. We used the definitions of 3 allergic diseases delineated by the Korean Standard Classification of Disease (KCD), ${ }^{31}$ and detailed codes for each disease are shown in Table 1. Outpatient and inpatient medical treatments due to symptoms of each allergic disease were counted for each sub-district based on a patient's dwelling address and divided by the total registered population in the corresponding sub-district. ${ }^{32}$ We counted each patient only once even if the patient had been treated multiple times under the same code. Table 2 summarizes the final disease prevalence data used for this study, the number of patients per 10,000 residents (male, female, and overall) for each disease in each of the 25 districts in Seoul.

The concentrations of ambient air pollutants were measured on a daily basis at 25 monitoring stations in Seoul during 2011, as collected by the Ministry of the Environment of Korea. Measurements of 5 major air pollutants were used to calculate annual average concentration in each of the 25 districts of Seoul: $\mathrm{SO}_{2}(\mathrm{ppb}), \mathrm{NO}_{2}(\mathrm{ppb}), \mathrm{O}_{3}(\mathrm{ppb}), \mathrm{CO}(\mathrm{ppb})$, and PM10 $\left(\mu \mathrm{g} / \mathrm{m}^{3}\right)$. As for meteorological data, the average values of temperature, wind speed, and precipitation in 2011 were obtained from the Korea Meteorological Administration in Seoul. Meteorological data were measured at 1 observatory per each district, which is different from the air pollution monitoring station. To better control for confounding factors, including socioeconomic covariates, in our regression analysis we included the following

Table 1. The Korean Standard Classification of Disease (KCD) codes used for defining three allergic diseases

\begin{tabular}{lll}
\hline & & \multicolumn{2}{c}{ Disease codes } \\
\hline Atopic dermatitis & L20 & Atopic dermatitis \\
Asthma & J45 & Allergic asthma \\
& J46 & $\begin{array}{c}\text { Status asthmaticus with predominantly allergic } \\
\text { asthma }\end{array}$ \\
Allergic rhinitis & J30 & Allergic rhinitis \\
\hline
\end{tabular}


Table 2. Description of data used (number of patients per 10,000 residents)

\begin{tabular}{|c|c|c|c|c|c|c|c|c|c|c|}
\hline & \multicolumn{3}{|c|}{ Atopic dermatitis } & \multicolumn{3}{|c|}{ Asthma } & \multicolumn{3}{|c|}{ Allergic rhinitis } \\
\hline & & Male & Female & All & Male & Female & All & Male & Female & All \\
\hline \multirow[t]{14}{*}{ Gangbuk } & Joong & 198 & 241 & 219 & 375 & 462 & 419 & 835 & 1,033 & 934 \\
\hline & Jongro & 180 & 211 & 196 & 368 & 439 & 404 & 965 & 1,093 & 1,029 \\
\hline & Yongsan & 166 & 197 & 182 & 299 & 331 & 315 & 923 & 1,111 & 1,019 \\
\hline & Gwangjin & 197 & 215 & 206 & 344 & 410 & 377 & 919 & 1,131 & 1,026 \\
\hline & Seongdong & 184 & 210 & 197 & 321 & 378 & 349 & 983 & 1,231 & 1,107 \\
\hline & Joonglang & 180 & 207 & 193 & 344 & 439 & 392 & 998 & 1,255 & 1,126 \\
\hline & Dongdaemun & 184 & 209 & 197 & 348 & 442 & 395 & 1,006 & 1,258 & 1,131 \\
\hline & Seongbuk & 209 & 230 & 220 & 401 & 451 & 426 & 1,061 & 1,245 & 1,154 \\
\hline & Dobong & 188 & 200 & 194 & 403 & 485 & 444 & 875 & 1,026 & 951 \\
\hline & Eunpyeong & 238 & 294 & 266 & 418 & 504 & 462 & 1,045 & 1,286 & 1,168 \\
\hline & Seodaemun & 258 & 304 & 282 & 469 & 586 & 528 & 1,051 & 1,262 & 1,158 \\
\hline & Mapo & 206 & 230 & 218 & 318 & 369 & 344 & 946 & 1,121 & 1,036 \\
\hline & Gangbuk & 192 & 200 & 196 & 445 & 563 & 505 & 953 & 1,203 & 1,079 \\
\hline & Nowon & 189 & 198 & 194 & 462 & 525 & 494 & 1,020 & 1,177 & 1,100 \\
\hline \multirow[t]{11}{*}{ Gangnam } & Gangseo & 178 & 194 & 186 & 386 & 469 & 428 & 986 & 1,176 & 1,082 \\
\hline & Guro & 195 & 209 & 202 & 352 & 428 & 390 & 966 & 1,177 & 1,071 \\
\hline & Youngdeungpo & 190 & 226 & 208 & 391 & 461 & 426 & 891 & 1,096 & 993 \\
\hline & Dongjak & 200 & 224 & 212 & 321 & 352 & 337 & 986 & 1,186 & 1,088 \\
\hline & Gwanak & 179 & 199 & 189 & 266 & 306 & 286 & 1,034 & 1,332 & 1,181 \\
\hline & Gangnam & 211 & 231 & 221 & 286 & 298 & 292 & 1,014 & 1,103 & 1,060 \\
\hline & Seocho & 256 & 266 & 261 & 314 & 337 & 326 & 1,098 & 1,217 & 1,159 \\
\hline & Songpa & 220 & 252 & 236 & 359 & 385 & 372 & 1,032 & 1,173 & 1,104 \\
\hline & Gangdong & 225 & 243 & 234 & 314 & 375 & 345 & 1,098 & 1,346 & 1,222 \\
\hline & Geumcheon & 144 & 165 & 154 & 361 & 458 & 409 & 642 & 840 & 739 \\
\hline & Yangcheon & 196 & 216 & 206 & 366 & 420 & 393 & 1,070 & 1,239 & 1,155 \\
\hline \multicolumn{2}{|c|}{ City of Seoul (overall) } & 201 & 224 & 213 & 361 & 423 & 392 & 993 & 1,188 & 1,092 \\
\hline
\end{tabular}

covariates aggregated at the sub-district level: (a) average of officially assessed land value (Korean Won per $\mathrm{m}^{2}$ ), (b) percentage of apartments, (c) number of households relying on welfare, as a proxy of household income level, (d) population density, (e) the number of taxi and transportation businesses, and (f) the percentage of college educated household heads.

Statistical modeling based on observed and interpolated data aggregated at the sub-district level allowed us to investigate PM10 and allergic diseases for ecological association, which is defined as "the association between 2 characteristics both measured at the aggregate level rather than the individual level."33 Epidemiological studies indicate the association between disease and behavioral as well as environmental determinants at the population level rather than at the individual level. ${ }^{34} \mathrm{Al}-$ though aggregate-level data are more accessible than those obtained at the individual level, interpretation is subjected to "ecological fallacy" which refers to errors resulting from inferences with the nature of individuals deduced from inference for the group or area to which those individuals belong. ${ }^{35,36}$ Despite the difficulties of interpreting aggregated data at the individual level, a number of methodological improvements have been developed to overcome ecological bias. ${ }^{37,38}$ When there are population risks that cannot be inferred from individual data, examining ecological association could be a useful way to reveal the possible impacts such risks could bring about. ${ }^{39}$ Also, ecological studies carried out in smaller areas are likely to be more informative when there is reasonable supposition that area characteristics are predictive of the prevalence of the target variable. ${ }^{40}$ Few studies have examined ecological associations between allergic diseases and ambient air pollutants, suggesting an important contribution from our study design.

We thus conducted statistical analyses of ecological associations between each of the 3 allergic diseases and PM10 concentration. First, we conducted an ordinary least squares (OLS) regression analysis of allergic disease prevalence using PM10 measurements, the air pollutant of primary interest, and meteorological measurements measured at the district level. The allergic disease prevalence variables were collected at the sub- 
district level and were aggregated for this analysis. Due to a mismatch between the levels of data aggregation, mainly because of the limited number of air pollution monitoring stations, we interpolated the concentration levels of PM10 from the 25 points to the entire surface of Seoul by using the ordinary kriging method. It has been demonstrated to be more accurate than other interpolation methods for estimating air pollutants. ${ }^{41,42}$ With a spherical model, we log transformed the data as a valid method for estimating levels of air pollutants while allowing "out-of-range predicted values" to be excluded. ${ }^{43}$ With the interpolated measurements of PM10 in each sub-district, another OLS regression analysis was performed to scrutinize ecological associations between PM10 and the prevalence of allergic diseases in Seoul. Various sub-district level socioeconomic factors were added to the OLS model to confirm if PM10 remains significantly associated with allergic diseases.

Next, in an attempt to assess the spatial heterogeneity in the estimated relationship between PM10 and allergic diseases, we performed GWR analysis, which has been widely applied in the public health literature. ${ }^{44-46}$ Using the results from the GWR model for atopic dermatitis, we created maps to visualize the main findings of concentrations of PM10 and atopic dermatitis risks across sub-districts in Seoul.

\section{RESULTS}

Descriptive information for all the variables used in our statistical models is summarized in Table 3 . The average level of PM10 remains the same after being interpolated (approximately $46.8 \mu \mathrm{g} / \mathrm{m}^{3}$ ), whereas its level of dispersion indicated by the standard deviation shrinks substantially (3.1 to $0.9 \mu \mathrm{g} / \mathrm{m}^{3}$ ). As measured at the district level, annual average precipitation was

Table 3. Descriptive statistics for variables used in our study ( $N=424)$

\begin{tabular}{|c|c|c|}
\hline & Variables & Mean (SD) \\
\hline \multirow[t]{2}{*}{ PM10 pollution } & $\begin{array}{l}\text { PM10 observed at the district level } \\
\left(\mu \mathrm{g} / \mathrm{m}^{3}\right)\end{array}$ & $46.8(3.1)$ \\
\hline & $\begin{array}{l}\text { PM10 interpolated at the sub-district } \\
\text { level }\left(\mu \mathrm{g} / \mathrm{m}^{3}\right)\end{array}$ & $46.7(0.9)$ \\
\hline \multirow{3}{*}{$\begin{array}{l}\text { Weather } \\
\text { factors }\end{array}$} & Temperature ( ${ }^{\circ} \mathrm{C}$; annual average) & $12.3(0.7)$ \\
\hline & Wind speed (m/sec; annual average) & $1.7(0.3)$ \\
\hline & Precipitation (cm; annual average) & $185(15.3)$ \\
\hline \multirow{6}{*}{$\begin{array}{l}\text { Socioeconomic } \\
\text { factors }\end{array}$} & Average land value $\left(\mathrm{KRW} / \mathrm{m}^{2}\right)$ & 3.7 million (2.6 million) \\
\hline & $\begin{array}{l}\% \text { households relying on welfare } \\
\text { subsidy }\end{array}$ & $3.6(2.9)$ \\
\hline & $\begin{array}{l}\% \text { household heads with college } \\
\text { education }\end{array}$ & $47.5(11.1)$ \\
\hline & Apartment rate $(\%)$ & $52.1(30.6)$ \\
\hline & Population density (person/km²) & $25,498(13,728)$ \\
\hline & $\begin{array}{l}\text { Number of clinics and hospitals } \\
\text { within the sub-district }\end{array}$ & $38.3(53.2)$ \\
\hline
\end{tabular}

$185 \mathrm{~cm}$, temperature was $12.3^{\circ} \mathrm{C}$, and wind speed was $0.7 \mathrm{~m} /$ sec. On average, $3.6 \%$ of households relied on welfare subsidies provided by the government, $52.1 \%$ of households lived in apartments, and $47.5 \%$ of heads of household had a college education. Average land value was 3.7 million Korean Won per square meter. Approximately 38 clinics were located on average within each sub-district.

Fig. 1A-C illustrate spatial variations in prevalence of the 3 allergic disease types overlaid with the PM10 contour in Seoul. Although it appears that the areas with higher levels of PM10 were clustered in the southeastern regions of Seoul, more scattered patterns were observed for the prevalence of all 3 allergic diseases. There is a substantial dissimilarity among the patterns of the disease prevalence.

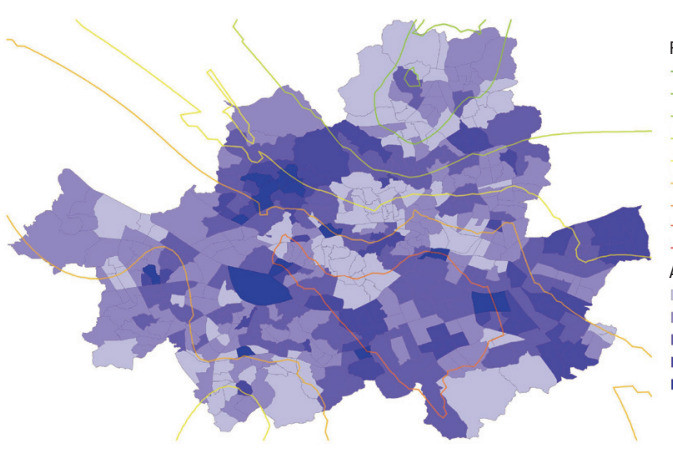

PM10 contours $\left(\mathrm{mcg} / \mathrm{m}^{3}\right)$ $-41.04$ -42.60
-44.02 $-45.30$ 46.46
-47.51 $-48.46$ $-49.32$ $-50.10$ AD patient counts (per 10,000) 93-177 178-220 - 221-262 - 263-347 - 348-553

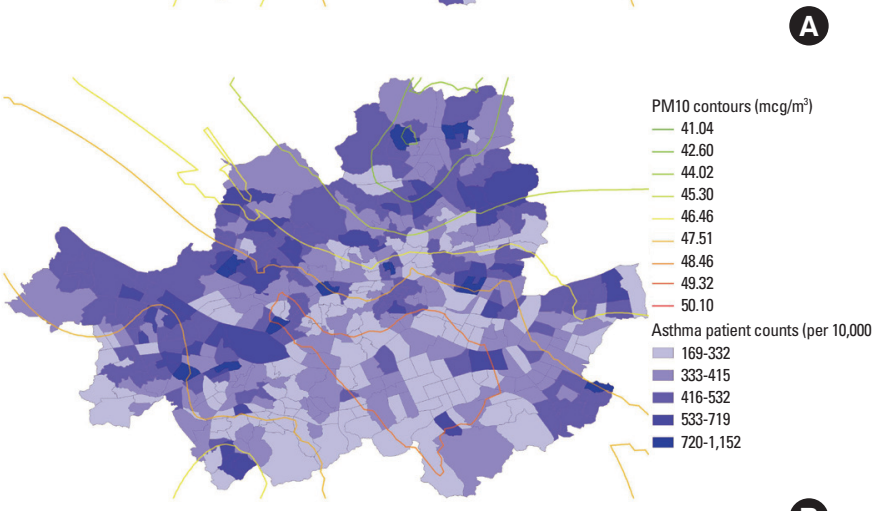

B

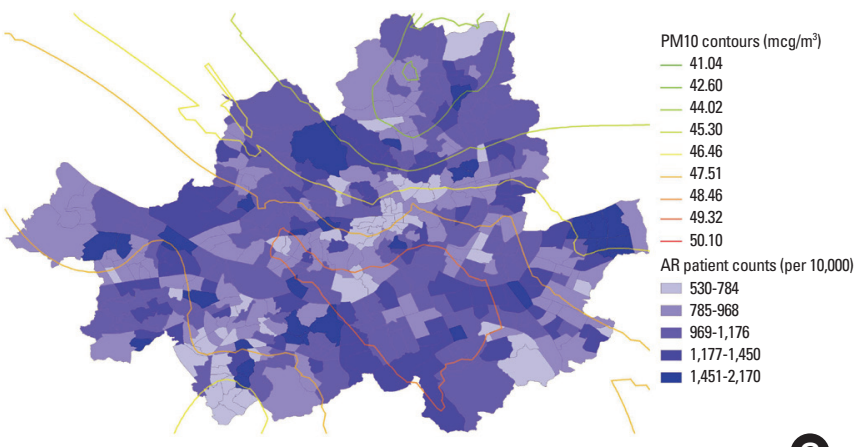

Fig. 1. Sub-district level patient counts with PM10 contour in Seoul (per 10,000). (A) atopic dermatitis, (B) asthma, and (C) allergic rhinitis. 
Table 4. Results of ordinary least square regression model for each disease $(N=424)$

\begin{tabular}{|c|c|c|c|c|c|c|c|c|c|c|}
\hline & & \multicolumn{3}{|c|}{ Atopic dermatitis } & \multicolumn{3}{|c|}{ Asthma } & \multicolumn{3}{|c|}{ Allergic rhinitis } \\
\hline & & Model 1 & Model 2 & Model 3 & Model 1 & Model 2 & Model 3 & Model 1 & Model 2 & Model 3 \\
\hline \multirow{2}{*}{$\begin{array}{l}\text { PM10 } \\
\text { pollution }\end{array}$} & PM10 observed at the district level $\left(\mu \mathrm{g} / \mathrm{m}^{3}\right)$ & $0.012^{\ddagger}$ & & & $-0.010^{\dagger}$ & & & 0.006 & & \\
\hline & PM10 interpolated at the sub-district level & & $0.052^{\ddagger}$ & $0.051^{\ddagger}$ & & $-0.061^{\ddagger}$ & -0.022 & & 0.006 & 0.006 \\
\hline \multirow{3}{*}{$\begin{array}{l}\text { Weather } \\
\text { factors }\end{array}$} & Temperature (annual average) & 0.002 & -0.015 & $-0.036^{*}$ & $-0.043^{\dagger}$ & -0.019 & -0.011 & 0.010 & 0.011 & -0.009 \\
\hline & Wind speed (annual average) & $-0.169^{\ddagger}$ & $-0.146^{\ddagger}$ & $-0.078^{*}$ & 0.061 & 0.036 & 0.036 & $-0.184^{\ddagger}$ & $-0.180^{\ddagger}$ & $-0.103^{\dagger}$ \\
\hline & Precipitation (annual average) & -0.0006 & -0.0002 & 0.0002 & -0.0015 & $-0.0021^{\dagger}$ & -0.0012 & 0.0008 & 0.0008 & $0.0013^{*}$ \\
\hline \multirow{6}{*}{$\begin{array}{l}\text { Socioeconomic } \\
\text { factors }\end{array}$} & Log of average land value $\left(\mathrm{KRW} / \mathrm{m}^{3}\right)$ & & & 0.016 & & & -0.044 & & & 0.002 \\
\hline & \% households relying on welfare subsidy & & & $-0.025^{\ddagger}$ & & & -0.006 & & & $-0.016^{\ddagger}$ \\
\hline & $\%$ household heads with college education & & & -0.002 & & & $-0.005^{\ddagger}$ & & & -0.001 \\
\hline & Apartment rate $(\%)$ & & & $0.002^{\ddagger}$ & & & $0.002^{\ddagger}$ & & & $0.002^{\ddagger}$ \\
\hline & Population density (person/m²) & & & -1.168 & & & 0.967 & & & -0.594 \\
\hline & $\begin{array}{l}\text { Log of number of clinics and hospitals } \\
\text { within the sub-district }\end{array}$ & & & $0.024^{*}$ & & & 0.004 & & & 0.023 \\
\hline \multirow[t]{2}{*}{ Model fit } & Constant & $5.18^{\ddagger}$ & $3.42^{\ddagger}$ & $3.30^{\ddagger}$ & $7.14^{\ddagger}$ & $9.36^{\ddagger}$ & $8.05^{\ddagger}$ & $6.70^{\ddagger}$ & $6.68^{\ddagger}$ & $6.56^{\ddagger}$ \\
\hline & Adjusted R square & 0.05 & 0.06 & 0.21 & 0.02 & 0.04 & 0.11 & 0.04 & 0.04 & 0.17 \\
\hline
\end{tabular}

${ }^{*} P<0.1 ;{ }^{\dagger} P<0.05 ;{ }^{\ddagger} P<0.01$.

Table 4 summarizes the results of the 3 OLS models for each allergic disease: (1) the observed level of PM10 with weather factors, (2) the interpolated level of PM10 with weather factors, and (3) the interpolated level of PM10 with both weather and socioeconomic factors. PM10 measurements were positively associated with the prevalence of atopic dermatitis $(P<0.01)$, and the size of its impact became greater when interpolated at the sub-district level. The coefficient for PM10 remained the same in the atopic dermatitis model even after controlling for various socioeconomic factors $(P<0.01)$. It is found that the atopic dermatitis prevalence was positively associated with the apartment dwelling rate and the number of clinics within the sub-district. Atopic dermatitis was negatively associated with temperature and wind speed, as well as the rate of households relying on welfare subsidy, which serves as a proxy for the poverty rate. No significant effect of PM10 was observed on asthma and allergic rhinitis when controlling for sub-district level socioeconomic factors. The welfare poverty indicator and apartment dwelling rate were found to be significant predictors for asthma and allergic rhinitis. Model fit was substantially improved by including socioeconomic variables. The atopic dermatitis and allergic rhinitis models had better fit than the asthma model.

Table 5 shows the results of GWR on inpatient and outpatient visits for each allergic disease at the sub-district level, using the interpolated PM10 levels, along with other covariates. The GWR model allows us to present both lower and upper quantiles of all the model coefficients, indicating how the simulated coefficients were distributed and identifying sub-districts with significant associations. In the atopic dermatitis model, we found that the middle $50 \%$ of the coefficients for the PM10 variable range from 0.04 to 0.157 across sub-districts in Seoul, as compared to the traditional OLS regression which estimated the PM10 parameter to be significant $(P<0.01)$ and equal to 0.051 for the entire city. This variability in the model parameter suggests that the association between the PM10 measurements and atopic dermatitis prevalence is not stationary at the subdistrict level.

The proportion of statistically significant GWR $t$-statistics for sub-districts is presented in Table 5. The interpolated PM10 variable is positively and significantly related to atopic dermatitis prevalence in about $39 \%$ of sub-districts, and is not significant in any of the remaining sub-districts. Although the PM10 variable was not significantly related to asthma prevalence in the global OLS regression model, the GWR results in Table 5 indicate that the $t$-statistic is negatively significant at the $P<0.05$ level in about $36 \%$ of sub-districts in Seoul, and positively significant in about $10 \%$. In addition, we found a similar spatial variation within the study area for the GWR model coefficients for most of the weather and socioeconomic factors, as summarized in Table 5. A Monte-Carlo test for assessing whether spatial variation in the relationship between each independent variable and the dependent variable is statistically significant across the city of Seoul, indicates significant evidence of spatial nonstationary status $(P<0.01)$.

Fig. 2 visualizes and identifies locations within Seoul where GWR performs relatively better in estimating predicted values of atopic dermatitis prevalence. The GWR model for atopic dermatitis appears to perform adequately. In a majority of sub-districts, the residuals of data were within \pm 0.2 from the predicted mean. In some sub-districts in the western region of Seoul, our models do not adequately explain the atopic dermatitis preva- 
Table 5. Results of geographically weighted regression (GWR) of inpatient or outpatient visits for each allergic disease $(\mathrm{N}=424)$

\begin{tabular}{|c|c|c|c|c|c|c|c|c|c|c|c|c|}
\hline & \multicolumn{4}{|c|}{ Atopic dermatitis } & \multicolumn{4}{|c|}{ Asthma } & \multicolumn{4}{|c|}{ Allergic rhinitis } \\
\hline & \multicolumn{2}{|c|}{ GWR coefficient } & \multicolumn{2}{|c|}{$\begin{array}{c}\% \text { of sub-districts } \\
\text { by significance of } \\
t \text {-statistic }\end{array}$} & \multicolumn{2}{|c|}{ GWR coefficient } & \multicolumn{2}{|c|}{$\begin{array}{c}\% \text { of sub-districts } \\
\text { by significance of } \\
t \text {-statistic }\end{array}$} & \multicolumn{2}{|c|}{ GWR coefficient } & \multicolumn{2}{|c|}{$\begin{array}{c}\% \text { of sub-districts } \\
\text { by significance o } \\
t \text {-statistic }\end{array}$} \\
\hline & $\begin{array}{l}\text { Lower } \\
\text { quartile }\end{array}$ & $\begin{array}{l}\text { Upper } \\
\text { quartile }\end{array}$ & $t \leq-1.96$ & $t \geq 1.96$ & $\begin{array}{l}\text { Lower } \\
\text { quartile }\end{array}$ & $\begin{array}{l}\text { Upper } \\
\text { quartile }\end{array}$ & $t \leq-1.96$ & $t \geq 1.96$ & $\begin{array}{l}\text { Lower } \\
\text { quartile }\end{array}$ & $\begin{array}{l}\text { Upper } \\
\text { quartile }\end{array}$ & $t \leq-1.96$ & $t \geq 1.96$ \\
\hline $\begin{array}{l}\text { PM10 interpolated } \\
\text { at the sub-district level }\end{array}$ & 0.040 & 0.157 & $0 \%$ & $39.4 \%$ & -0.122 & 0.023 & $35.6 \%$ & $10.4 \%$ & -0.026 & 0.013 & $0 \%$ & $0 \%$ \\
\hline $\begin{array}{l}\text { Temperature } \\
\text { (annual average) }\end{array}$ & -0.055 & -0.010 & $34.2 \%$ & $0 \%$ & -0.028 & 0.047 & $8.3 \%$ & $7.1 \%$ & -0.027 & 0.027 & $20.3 \%$ & $11.5 \%$ \\
\hline $\begin{array}{l}\text { Wind speed } \\
\text { (annual average) }\end{array}$ & -0.481 & -0.008 & $17.9 \%$ & $0 \%$ & -0.319 & 0.542 & $17.2 \%$ & $23.3 \%$ & -0.529 & -0.028 & $58.7 \%$ & $0 \%$ \\
\hline $\begin{array}{l}\text { Precipitation } \\
\text { (annual average) }\end{array}$ & -0.048 & 0.001 & $9.7 \%$ & $1.7 \%$ & -0.045 & 0.028 & $23.3 \%$ & $8.5 \%$ & 0.0006 & 0.0041 & $0 \%$ & $29.5 \%$ \\
\hline $\begin{array}{l}\text { Log of average land value } \\
\left(\mathrm{KRW} / \mathrm{m}^{3}\right)\end{array}$ & -0.027 & 0.037 & $14.4 \%$ & $1.6 \%$ & -0.017 & 0.032 & $0 \%$ & $0.01 \%$ & -0.016 & 0.022 & $3.1 \%$ & $0 \%$ \\
\hline $\begin{array}{l}\% \text { HH relying on welfare } \\
\text { subsidy }\end{array}$ & -0.099 & -0.047 & $71.0 \%$ & $0 \%$ & -0.053 & -0.016 & $25.9 \%$ & $0 \%$ & -0.058 & -0.040 & $89.2 \%$ & $0 \%$ \\
\hline $\begin{array}{l}\% \text { HH heads with college } \\
\text { education }\end{array}$ & -0.071 & 0.018 & $19.3 \%$ & $1.7 \%$ & -0.102 & -0.006 & $26.4 \%$ & $0.01 \%$ & -0.016 & 0.018 & $2.1 \%$ & $4.5 \%$ \\
\hline Apartment rate (\%) & 0.040 & 0.092 & $0 \%$ & $63.4 \%$ & 0.069 & 0.101 & $0 \%$ & $83.0 \%$ & 0.071 & 0.085 & $0 \%$ & $100 \%$ \\
\hline $\begin{array}{l}\text { Population density } \\
\left.\text { (person } / \mathrm{m}^{2}\right)\end{array}$ & -0.029 & 0.007 & $6.6 \%$ & $0 \%$ & 0.001 & 0.032 & $3.3 \%$ & $8.5 \%$ & -0.019 & -0.004 & $0 \%$ & $0 \%$ \\
\hline $\begin{array}{l}\text { Log of number of clinics and } \\
\text { hospitals within sub-district }\end{array}$ & -0.004 & 0.029 & $0 \%$ & $14.2 \%$ & -0.032 & 0.011 & $0.01 \%$ & $0 \%$ & -0.002 & 0.030 & $0 \%$ & $21.2 \%$ \\
\hline Constant & 5.294 & 5.389 & $0 \%$ & $100 \%$ & 5.938 & 6.011 & $0 \%$ & $100 \%$ & 6.898 & 6.926 & $0 \%$ & $94.3 \%$ \\
\hline Adjusted R square & & & & & & & 32 & & & & & \\
\hline
\end{tabular}

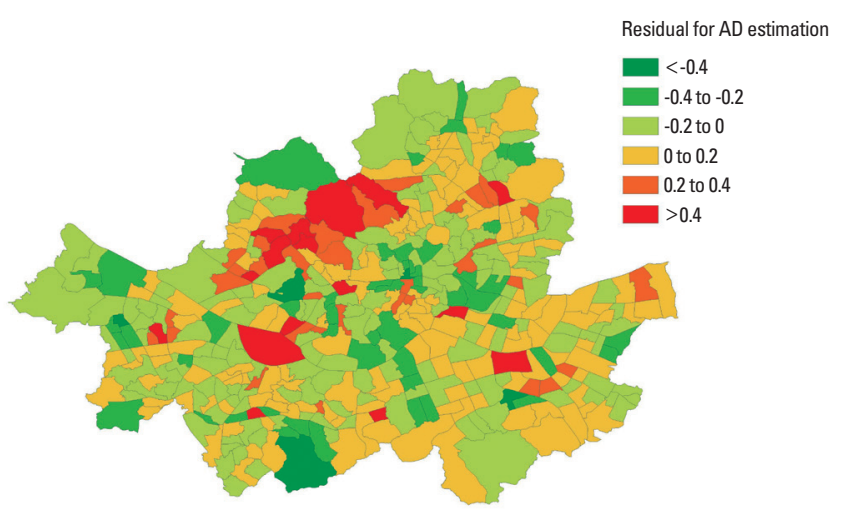

Fig. 2. Map of the residuals of GWR model for atopic dermatitis by sub-districts in Seoul.

lence.

In order to explore the spatial patterns of our GWR results, we generated a map (Fig. 3) that represents the geographic distribution of statistical association of interpolated PM10 and atopic dermatitis prevalence. The darkest shades are used to depict sub-districts with a positive $t$-statistic larger than or equal to 2.58 , the lighter shades are used to display sub-districts with a positive $t$-statistic greater than or equal to 1.96 , and no shading

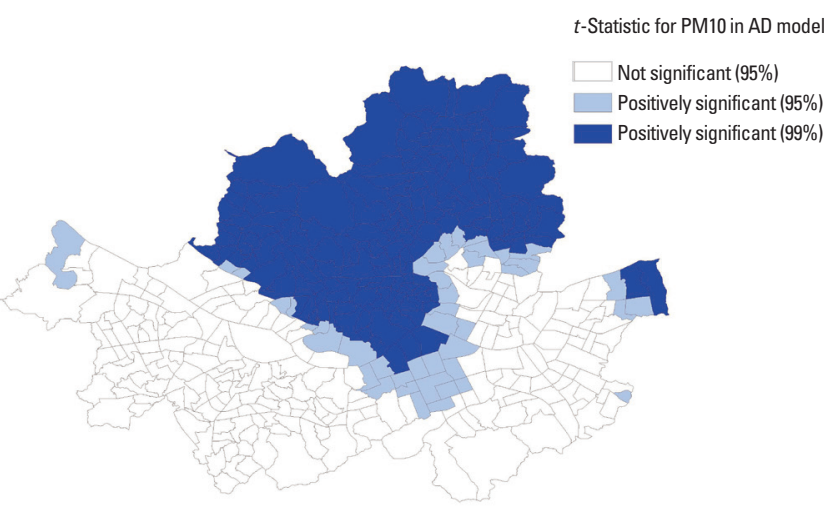

Fig. 3. Map of $t$-statistics for the PM10 coefficient in the atopic dermatitis model by sub-district in Seoul.

represents sub-districts with a $t$-statistic between -1.96 and +1.96 . This map illustrates not only the areas where the PM10 variable has a strong statistical influence on atopic dermatitis prevalence in the model, but also important local variation not captured by the global OLS model. In general, the PM10 measurement is positively associated with atopic dermatitis prevalence across the sub-districts in the northern region of Seoul (called "Gangbuk") but is not significant mostly in the southern 
Table 6. Comparison of OLS results for the atopic dermatitis model between Gangnam and Gangbuk regions in Seoul

\begin{tabular}{|c|c|c|}
\hline & $\begin{array}{c}\text { Gangnam } \\
\text { region } \\
(\mathrm{N}=84)\end{array}$ & $\begin{array}{c}\text { Gangbuk } \\
\text { region } \\
(\mathrm{N}=223)\end{array}$ \\
\hline PM10 interpolated at the sub-district level & N.S. & $0.149^{\dagger}$ \\
\hline Temperature (annual average) & N.S. & $-0.133^{\dagger}$ \\
\hline Wind speed (annual average) & N.S. & N.S. \\
\hline Precipitation (annual average) & N.S. & N.S. \\
\hline Log of average land value $\left(\mathrm{KRW} / \mathrm{m}^{3}\right)$ & N.S. & $-0.125^{\dagger}$ \\
\hline$\%$ households relying on welfare subsidy & $-0.034^{\dagger}$ & $-0.027^{\dagger}$ \\
\hline$\%$ household heads with college education & N.S. & $-0.009^{\dagger}$ \\
\hline Apartment rate (\%) & N.S. & $0.003^{\dagger}$ \\
\hline Population density (person/m²) & $-3.404^{\dagger}$ & N.S. \\
\hline $\begin{array}{l}\text { Log of number of clinics and hospitals within } \\
\text { sub-district }\end{array}$ & N.S. & N.S. \\
\hline Constant & N.S. & $2.002^{*}$ \\
\hline Adjusted R square & 0.34 & 0.30 \\
\hline
\end{tabular}

${ }^{*} P<0.1 ;{ }^{\dagger} P<0.01$.

N.S., Not significant.

region of Seoul below the Han River (called "Gangnam”).

To further demonstrate the utility of a modeling approach incorporating a spatially-varying relationship between PM10 measurements and atopic dermatitis prevalence, Table 6 compares the OLS results for the atopic dermatitis model from the 2 distinct regions in Seoul, Gangnam and Gangbuk. The OLS results for these regions indicate that a majority of the variables, including the PM10 measurements, were found to be statistically significant only in Gangbuk. Most of the variables in the Gangnam region were insignificant, except for a poverty indicator. This comparison exercise demonstrates how the impacts of some explanatory factors vary spatially and thus emphasizes the limits of using a traditional OLS model, which could fail to incorporate local variations of environmental and socioeconomic effects on allergic disease prevalence.

\section{DISCUSSION}

This study examined a spatial association between the level of PM10 and the prevalence of 3 allergic diseases in Seoul, Korea by using inpatient and outpatient count data aggregated at the sub-district level and the average daily concentration of PM10 interpolated to the 424 sub-districts in the city. A series of statistical models using the data indicated that PM10 was a significant predictor of atopic dermatitis, whereas no significant effect of PM10 was observed on allergic rhinitis and asthma when socioeconomic and meteorological factors were controlled for. PM10 effects on atopic dermatitis were not consistent throughout Seoul, with statistical significance only in the Gangbuk region.

The prevalence of allergic diseases is rising dramatically in both developed and developing countries, and the development and exacerbation of allergic diseases may be attributed to rapidly increasing air pollution levels. Clinical research suggests environmental factors are important in allergic diseases, but the relative importance may vary spatially when accounting for other factors. Clinical studies may provide insufficient guidance for policy at the regional level and can be supplemented by epidemiologic studies.

To the authors' knowledge, this is the first study to assess the level of ecological association between PM10 measurements and allergic diseases in Korea using GIS-based spatial modeling techniques. Although this research does not reveal causal links between elevated PM10 and allergic diseases, the findings contribute to policy guidelines regarding regional-level environmental factors. GIS and spatial statistical techniques, such as kriging and GWR, play a critical role in ensuring the robustness of results and addressing the limitations of air pollution and disease prevalence data. The implication of the GWR models used in this study is that uniform policy interventions may not work due to significant regional variations in environmental and socioeconomic factors for allergic diseases. ${ }^{47}$

Only the prevalence of atopic dermatitis was significantly associated with the level of PM10 interpolated at the sub-district level in this study. In general, sensitization to allergens could play a major role in developing allergic diseases. The rates of sensitization to allergens in South Korea were $80.9 \%$ for asthma and $89.9 \%$ for allergic rhinitis; ${ }^{48,49}$ however, while that for atopic dermatitis was only $60.0 \% .^{50}$ This may indicate that atopic dermatitis could be influenced more by air pollution factors, such as PM10, than the other diseases, due to its lower sensitization rate for other allergens. This finding is consistent with the relatively small associations of air pollution with the prevalence of asthma or allergic rhinitis observed in this study.

The GIS-based statistical analyses using spatially-aggregated data utilized in this study effectively uses the routine public health and environmental data in Korea, such as the National Health Insurance Corporation (NHIC) data, the Korea National Health and Nutrition Examination Survey (KNHANES) data, and various environmental monitoring data. These datasets tend to be collected repeatedly (e.g. every year or month) and at more disaggregated administrative units (e.g. sub-districts). Such data are becoming readily available to medical researchers and public health professionals, and can be widely analyzed with other administrative database for relatively low cost to better address various concerns of allergic diseases.

GIS-based spatial modeling techniques play a role in evaluating impacts of variation of air pollution impacts on allergic diseases, which could provide valuable policy guidance for environmental and public health policymakers. Identifying spatial patterns may allow officials to concentrate on high-risk areas. Targeted policies, such as enhancing accessibility to hospitals or community health centers, could effectively improve public 
health by mediating environmental risk factors and by efficiently allocating limited resources. Regionally-tailored strategies would better manage environmental risk factors associated with allergic diseases. ${ }^{15}$

\section{ACKNOWLEDGMENTS}

This research was supported by Basic Science Research Program through the National Research Foundation of Korea (NRF) funded by the Ministry of Education (grant number: NRF-2012R1A1A2006816). This support is greatly appreciated.

\section{REFERENCES}

1. Ministry of Environment (KR). Plans for the prevention and control of allergic diseases. Seoul: Ministry of Environment; 2011.

2. Jenerowicz D, Silny W, Dańczak-Pazdrowska A, Polańska A, Osmola-Mańkowska A, Olek-Hrab K. Environmental factors and allergic diseases. Ann Agric Environ Med 2012;19:475-81.

3. Nickmilder M, Bernard A. Ecological association between childhood asthma and availability of indoor chlorinated swimming pools in Europe. Occup Environ Med 2007;64:37-46.

4. Zock JP, Jarvis D, Luczynska C, Sunyer J, Burney P; European Community Respiratory Health Survey. Housing characteristics, reported mold exposure, and asthma in the European Community Respiratory Health Survey. J Allergy Clin Immunol 2002;110:285-92.

5. Seo S, Kim D, Paul C, Yoo Y, Choung JT. Exploring household-level risk factors for self-reported prevalence of allergic diseases among low-income households in Seoul, Korea. Allergy Asthma Immunol Res 2014;6:421-7.

6. Morgenstern V, Zutavern A, Cyrys J, Brockow I, Koletzko S, Krämer $\mathrm{U}$, et al. Atopic diseases, allergic sensitization, and exposure to traffic-related air pollution in children. Am J Respir Crit Care Med 2008;177:1331-7.

7. Suárez-Varela MM, Gallardo-Juan A, García-Marcos L, GimenoClemente N, Silvarrey-Varela ÁL, Miner-Canflanca I, et al. The impact of atmospheric pollutants on the prevalence of atopic eczema in 6-7-year-old schoolchildren in Spain; ISAAC Phase III. Iran J Allergy Asthma Immunol 2013;12:220-7.

8. Zmirou D, Gauvin S, Pin I, Momas I, Sahraoui F, Just J, et al. Traffic related air pollution and incidence of childhood asthma: results of the Vesta case-control study. J Epidemiol Community Health 2004; 58:18-23.

9. Gauderman WJ, Avol E, Lurmann F, Kuenzli N, Gilliland F, Peters J, et al. Childhood asthma and exposure to traffic and nitrogen dioxide. Epidemiology 2005;16:737-43.

10. Pénard-Morand C, Charpin D, Raherison C, Kopferschmitt C, Caillaud D, Lavaud F, et al. Long-term exposure to background air pollution related to respiratory and allergic health in schoolchildren. Clin Exp Allergy 2005;35:1279-87.

11. McConnell R, Islam T, Shankardass K, Jerrett M, Lurmann F, Gilliland F, et al. Childhood incident asthma and traffic-related air pollution at home and school. Environ Health Perspect 2010;118: 1021-6.

12. Krämer U, Koch T, Ranft U, Ring J, Behrendt H. Traffic-related air pollution is associated with atopy in children living in urban areas. Epidemiology 2000;11:64-70.
13. Hajat S, Haines A, Atkinson RW, Bremner SA, Anderson HR, Emberlin J. Association between air pollution and daily consultations with general practitioners for allergic rhinitis in London, United Kingdom. Am J Epidemiol 2001;153:704-14.

14. Heinrich J, Wichmann HE. Traffic related pollutants in Europe and their effect on allergic disease. Curr Opin Allergy Clin Immunol 2004;4:341-8.

15. Kim J, Kim EH, Oh I, Jung K, Han Y, Cheong HK, et al. Symptoms of atopic dermatitis are influenced by outdoor air pollution. J Allergy Clin Immunol 2013;132:495-8.e1.

16. Lipsett M, Hurley S, Ostro B. Air pollution and emergency room visits for asthma in Santa Clara County, California. Environ Health Perspect 1997;105:216-22.

17. Donaldson K, Gilmour MI, MacNee W. Asthma and PM10. Respir Res 2000;1:12-5.

18. Lee JT, Kim H, Song H, Hong YC, Cho YS, Shin SY, et al. Air pollution and asthma among children in Seoul, Korea. Epidemiology 2002;13:481-4.

19. Pénard-Morand C, Charpin D, Raherison C, Kopferschmitt C, Caillaud D, Lavaud F, et al. Long-term exposure to background air pollution related to respiratory and allergic health in schoolchildren. Clin Exp Allergy 2005;35:1279-87.

20. Oh IB, Lee JH, Sim CS, Kim Y, Yoo CI. An association between air pollution and the prevalence of allergic rhinitis in the Ulsan metropolitan region. J Environ Health Sci 2010;36:465-71.

21. Lee YL, Shaw CK, Su HJ, Lai JS, Ko YC, Huang SL, et al. Climate, traffic-related air pollutants and allergic rhinitis prevalence in middle-school children in Taiwan. Eur Respir J 2003;21:964-70.

22. Baek M, Jung J, Jang T, Kim S, Ko K, Kim Y. The effect of PM10 on the symptoms of allergic rhinitis during spring. Otolaryngol Head Neck Surg 2013;149:P257-8.

23. Lee JT, Kim H, Song H, Hong YC, Cho YS, Shin SY, et al. Air pollution and asthma among children in Seoul, Korea. Epidemiology 2002;13:481-4.

24. Goldhagen J, Remo R, Bryant T 3rd, Wludyka P, Dailey A, Wood D, et al. The health status of southern children: a neglected regional disparity. Pediatrics 2005;116:e746-53.

25. Maantay J. Asthma and air pollution in the Bronx: methodological and data considerations in using GIS for environmental justice and health research. Health Place 2007;13:32-56.

26. Ayres-Sampaio D, Teodoro AC, Sillero N, Santos C, Fonseca J, Freitas A. An investigation of the environmental determinants of asthma hospitalizations: an applied spatial approach. Appl Geogr 2014; 47:10-9.

27. Akçakaya N, Kulak K, Hassanzadeh A, Camcioğlu Y, Cokuğraş H. Prevalence of bronchial asthma and allergic rhinitis in Istanbul school children. Eur J Epidemiol 2000;16:693-9.

28. Byun H, Bae H, Kim D, Shin H, Yoon C. Effects of socioeconomic factors and human activities on children's PM(10) exposure in inner-city households in Korea. Int Arch Occup Environ Health 2010; 83:867-78.

29. Lee JT, Son JY, Kim H, Kim SY. Effect of air pollution on asthma-related hospital admissions for children by socioeconomic status associated with area of residence. Arch Environ Occup Health 2006; 61:123-30.

30. Bergmann RL, Edenharter G, Bergmann KE, Lau S, Wahn U. Socioeconomic status is a risk factor for allergy in parents but not in their children. Clin Exp Allergy 2000;30:1740-5.

31. Statistics Korea. Korean standard classification of diseases [Inter- 
net]. Daejeon: Statistics Korea; 2011 [cited 2015 Apr 28]. Available from: http://kostat.go.kr/kssc/main/MainAction.do?method=sub \&catgrp $=$ ekssc\&catidl $1=$ ekssc 03 .

32. Hwang SH, Jung SY, Lim DH, Son BK, Kim JH, Yang JM, et al. Epidemiology of allergic rhinitis in Korean children. Allergy Asthma Respir Dis 2013;1:321-32.

33. McLean I, McMillan A. The concise Oxford dictionary of politics. 3rd ed. New York (NY): Oxford University Press; 2009.

34. Plummer M, Clayton D. Estimation of population exposure in ecological studies. J R Stat Soc Series B Methodol 1996;58:113-26.

35. Connor MJ, Gillings D. An empiric study of ecological inference. Am J Public Health 1984;74:555-9.

36. Piantadosi S, Byar DP, Green SB. The ecological fallacy. Am J Epidemiol 1988;127:893-904.

37. Guthrie KA, Sheppard L. Overcoming biases and misconceptions in ecological studies. J R Stat Soc Ser A Stat Soc 2001;164:141-54.

38. Lasserre V, Guihenneuc-Jouyaux C, Richardson S. Biases in ecological studies: utility of including within-area distribution of confounders. Stat Med 2000;19:45-59.

39. Breslin FC, Smith P, Dunn JR. An ecological study of regional variation in work injuries among young workers. BMC Public Health 2007;7:91.

40. Rezaeian M, Dunn G, St Leger S, Appleby L. Ecological association between suicide rates and indices of deprivation in the north west region of England: the importance of the size of the administrative unit. J Epidemiol Community Health 2006;60:956-61.

41. Joseph J, Sharif HO, Sunil T, Alamgir H. Application of validation data for assessing spatial interpolation methods for 8-h ozone or other sparsely monitored constituents. Environ Pollut 2013;178: 411-8.

42. Son JY, Bell ML, Lee JT. Individual exposure to air pollution and lung function in Korea: spatial analysis using multiple exposure approaches. Environ Res 2010;110:739-49.

43. Liao D, Peuquet DJ, Duan Y, Whitsel EA, Dou J, Smith RL, et al. GIS approaches for the estimation of residential-level ambient PM concentrations. Environ Health Perspect 2006;114:1374-80.

44. Cummins S, Clary C, Lewis D, Flint E, Smith N, Kestens Y. PP39 Relative versus absolute measures of the neighbourhood food environment and diet in the ORiEL Study: a geographically weighted regression approach. J Epidemiol Community Health 2014;68:A63.

45. Yang TC, Matthews SA. Understanding the non-stationary associations between distrust of the health care system, health conditions, and self-rated health in the elderly: a geographically weighted regression approach. Health Place 2012;18:576-85.

46. Carrel M, Escamilla V, Messina J, Giebultowicz S, Winston J, Yunus $\mathrm{M}$, et al. Diarrheal disease risk in rural Bangladesh decreases as tubewell density increases: a zero-inflated and geographically weighted analysis. Int J Health Geogr 2011;10:41.

47. Ali K, Partridge MD, Olfert MR. Can geographically weighted regressions improve regional analysis and policy making? Int Reg Sci Rev 2007;30:300-29.

48. Shim E, Yu J. Relationship between duration of disease and bronchial responsiveness in 6-8 years old children with asthma. Allergy Asthma Respir Dis 2014;2:23-9.

49. Park HB, Kim YH, Kim MJ, Kim HS, Lee HS, Han YK, et al. Forced expiratory flow between $25 \%$ and $75 \%$ of vital capacity as a predictor for bronchial hyperresponsiveness in children with allergic rhinitis. Allergy Asthma Respir Dis 2013;1:60-6.

50. Kim HS, Jung JI, Suh SB, Jung JA. Characteristics between IgE mediated and non-IgE mediated atopic dermatitis in children. Allergy Asthma Respir Dis 2013;1:339-43. 